\title{
Detection of inflammatory bowel disease in adults and children: evaluation of a new isotopic technique
}

\author{
D J DAWSON, A N KHAN, V MILLER, J F RATCLIFFE, D R SHREEVE
}

\begin{abstract}
The distribution of radioactivity after the oral administration of sucralfate labelled with technetium-99m was studied in 33 patients with Crohn's disease (13 adults, 20 children), 10 with ulcerative colitis (four adults), and 29 controls ( 23 with upper intestinal disease, four irritable bowel, one hypolactasia, and one malrotation of the gut). Positive scans were obtained in all patients with ulcerative colitis and 29 of 31 with active Crohn's disease. The scans of two patients with inactive Crohn's disease were negative. There were two false negative scans in patients with Crohn's colitis and one false positive scan. Overall, sensitivity was $95 \%$ and specificity $97 \%$.

Comparison with radiology in 39 patients showed similar distribution of disease in 24 and more extensive disease in $\mathbf{1 2}$. The scan was inexpensive, simple to perform, well tolerated, allowed small and large bowel to be visualised simultaneously, and used a lower dose of radiation than barium studies. It may prove useful as a screening test for inflammatory bowel disease and in the serial assessment of disease activity.
\end{abstract}

\section{Introduction}

The assessment of the extent and severity of inflammatory bowel disease usually requires radiography and endoscopy, which carry risks of complication, may use high doses of radiation, and are poorly tolerated by children and severely ill patients. ${ }^{1-5} \mathrm{~A}$ non-

\footnotetext{
Departments of Gastroenterology and Diagnostic Imaging, North Mancheste General Hospital, Manchester M8 6RB

D J DAWSON, BSC, MRCP, senior medical registrar

A N KHAN, MRCP, FRCR, consultant radiologist

D R SHREEVE, FRCP, FRCPED, consultant physician

Booth Hall Children's Hospital, Manchester

V MILLER, FRCS, FRCP, consultant paediatrician

J F RATCLIFFE, FRCS, FRCP, consultant paediatric radiologist

Correspondence to: Dr Khan.
}

invasive technique using little radiation and capable of detecting both small and large bowel inflammatory disease would thus be an important advance.

Sucralfate (Ayerst Laboratories), an aluminium salt of polysulphated sucrose used in the treatment of peptic ulcers, has been shown to bind selectively at the site of mucosal ulceration ${ }^{6-8}$ and, after complexing to technetium- $99 \mathrm{~m}$, has been used to detect peptic ulcers. ${ }^{9}{ }^{10}$ As mucosal ulceration occurs in both Crohn's disease and ulcerative colitis the aim of this study was to determine whether sucralfate labelled with ${ }^{99 m} \mathrm{Tc}$ enabled inflammatory bowel disease to be visualised and, if so, to compare the findings with those of conventional barium radiology. As inflammatory bowel disease in children may differ from that in adults in its presentation, course, and prognosis ${ }^{11 \cdot 13}$ we assessed the isotope scan in both adults and children.

\section{Subjects and methods}

Thirteen adults had Crohn's disease (seven men; median age 23, range 16 48 years) and four had ulcerative colitis (two men; median age 37, range 1670 years). All had active disease according to the modified Crohn's activity index of Harvey and Bradshaw ${ }^{14}$ or the criteria of Truelove and Witts. ${ }^{15}$ Twenty adults acted as controls (13 men; median age $57 \cdot 5$, range $29-77$ years); seven had gastric ulcers, eight duodenal ulcers, two carcinoma of the stomach, two peptic oesophagitis, and one irritable bowel syndrome.

Twenty children had Crohn's disease (eight boys; median age 12, range 316 years), which was inactive in two. Six had ulcerative colitis (five boys; median age 9 , range 3-14 years). Nine children acted as controls (six boys; median age 10, range 6 months-15 years); three had irritable bowel syndrome, four duodenal ulcers, one congenital hypolactasia, and one congenital malrotation of the gut.

\section{TECHNETIUM-99M SUCRALFATE SCANNING}

Sucralfate labelled with ${ }^{99 m} \mathrm{Tc}$ was prepared as described previously. ${ }^{10}$ After fasting overnight adults drank $250 \mathrm{mg}$ sucralfate containing 130-200 $\mathrm{MBq}(3 \cdot 5-5.4 \mathrm{mCi})^{99 m} \mathrm{Tc}$ suspended in $200 \mathrm{ml}$ iced water followed by $10 \mathrm{mg}$ metaclopromide syrup and $500 \mathrm{ml}$ mannitol $(10 \%)$ to hasten gastric emptying and intestinal transit and produce an osmotic purgation. Children were given $2.5 \mathrm{MBq}(68 \mu \mathrm{Ci}){ }^{99 m} \mathrm{Tc}$ sucralfate $/ \mathrm{kg}$ body weight and only 250 $\mathrm{ml}$ mannitol. Serial isotope scans of the abdomen were obtained between two 
and six hours and 20 and 24 hours. Rectal washout was performed before the later scans were obtained. Scans were interpreted by an experienced radiologist without knowledge of the clinical or radiological findings and assessed, firstly, as positive or negative for disease and, secondly, for distribution of disease (ileocolonic or colonic for Crohn's disease, proximal extent of disease in ulcerative colitis).

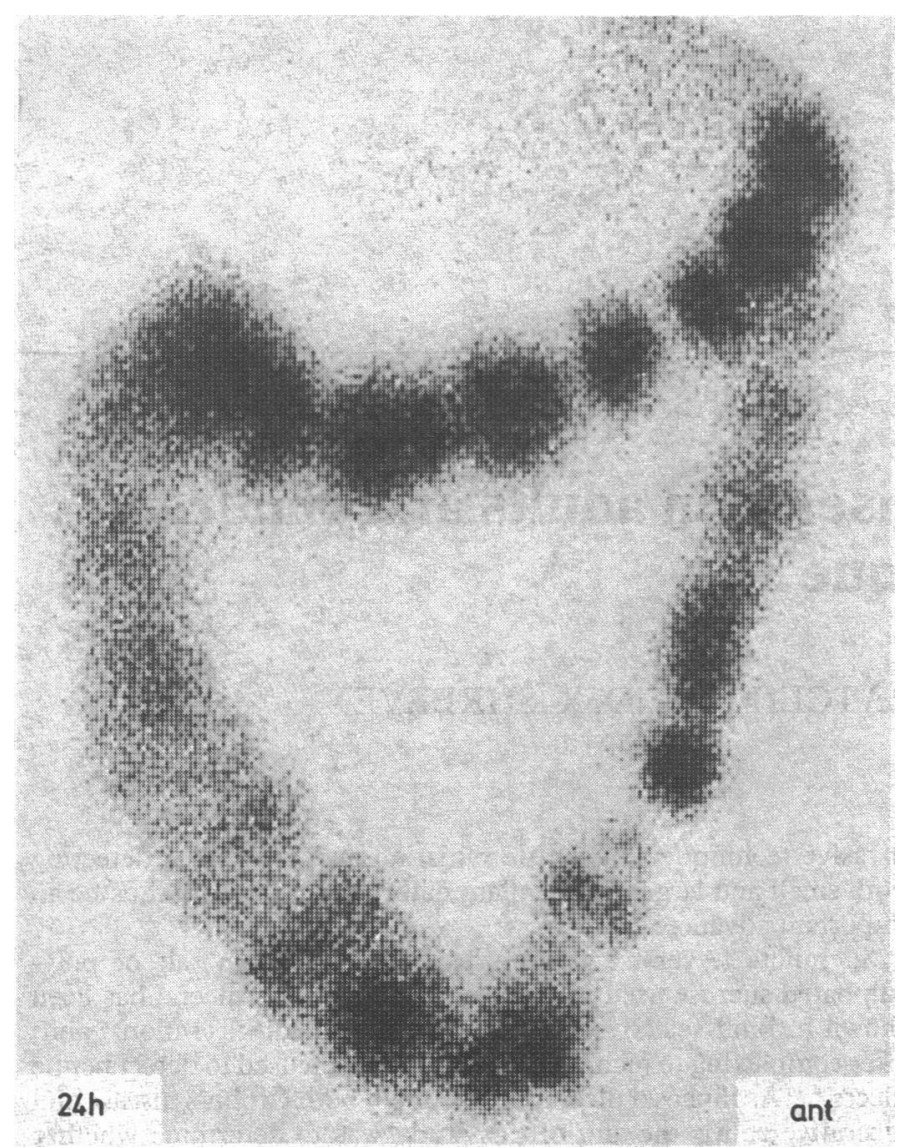

FIG 1-Anterior abdominal scintigram 24 hours after ingestion of $250 \mathrm{mg}$ sucralfate labelled with $200 \mathrm{MBq}{ }^{99 \mathrm{~m}} \mathrm{Tc}$ by control subject with no inflammatory bowel disease. Activity outlines colon in characteristic pattern following the colonic haustrations. No activity remains in stomach or small bowel.

Conversion: $S I$ to traditional units-1 $\mathrm{MBq} \approx 0.3 \mu \mathrm{Ci}$.

Recent radiographs were available for comparison in all adults and 22 children with inflammatory bowel disease. Colonoscopy was performed in seven of nine subjects in whom the appearance of the colon differed in the ${ }^{9 m} \mathrm{mc}$ sucralfate scan and by barium studies. Barium follow through and barium enema examinations were not performed in controls.

\section{Results}

\section{INTERPRETATION OF SCANS}

In controls isotope activity in the stomach and small intestine was seen only between two and six hours, although in some subjects a second image of the stomach was obtained at 20-24 hours, suggesting re-excretion of free technetium. Images in normal small bowel always showed a diffuse distribution of isotope with no persistent, localised areas of activity. In the colon images were sometimes obtained as early as two hours and usually by six hours; at 20-24 hours activity had either completely resolved or showed a characteristic distribution outlining the haustral pattern of the colon (fig 1), which changed rapidly with time.

Scans showing inflammatory bowel disease were distinct. Subjects with Crohn's disease of the small bowel showed intense activity localised to the affected areas (fig 2). In Crohn's colitis activity of disease was not continuous (fig 3) whereas that in ulcerative colitis was intense and uniform in distribution (fig 4). Appearances differed from controls in the intensity of activity and its persistence for several hours at a single site; only rarely was there any difficulty in distinguishing affected bowel from faecal activity.
The appearances of the scans did not differ appreciably between adults and children. The procedure was well tolerated in all but one child, who developed dehydration secondary to the mannitol preparation.

\section{DETECTION OF DISEASE}

Table I gives the results of the scans, which were positive in all patients with ulcerative colitis and 29 of 31 patients with active Crohn's disease. Negative scans were obtained in two patients with inactive Crohn's disease. Two false negative scans occurred (one in an adult and the other in a child with Crohn's colitis). Only one false positive scan was found, in the patient with congenital malrotation of the gut. Scanning was repeated in three subjects with Crohn's disease; the distribution of the isotope was the same as that seen on the original scan in two and in the third showed extension at a time of clinical deterioration.

The sensitivity and specificity of the technique were high and were similar in adults and children (table II).

\section{COMPARISON WITH RADIOLOGY}

The radiological distribution of disease in 29 subjects with Crohn's disease (13 adults) was ileal in 14, ileocolonic in eight, and colonic in seven. The distribution of disease determined by the ${ }^{99 m} \mathrm{Tc}$ sucralfate scan agreed with

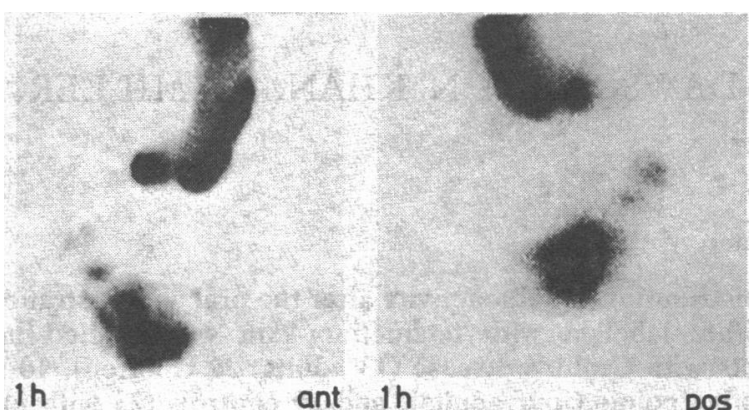

ant

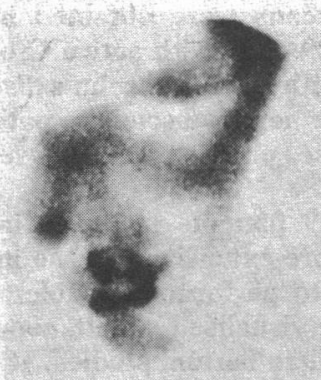

$2 \mathrm{~h}$
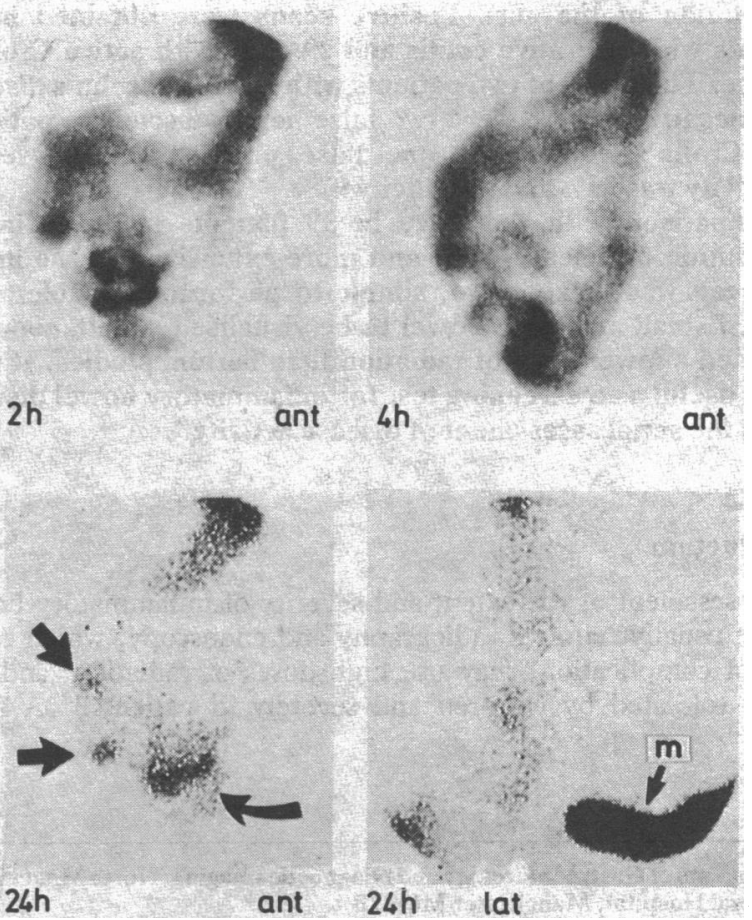

FIG 2-99-Tc sucralfate scintigrams in patient with ileocaecal Crohn's disease. At one hour activity is in stomach, duodenum, and distal small bowel but moves to ad four hour scans. Intense activity present in ileum caecum at two hours is persistent even at 24 hours (straight arrows). The curved arrow depicts rectal activity (localised in the lateral view (lat), which has an external marker $(M)$ on the anterior abdominal wall), which resolved after rectal washout (scan not shown). Persistent activity in the stomach at 24 hours suggests excretion of free technetium. 
the results of radiology in 20 subjects. Scans were negative in two subjects with colonic disease radiologically and in a third with ileocolonic disease radiologically, the scan showed only three of four lesions present on the barium enema. Conversely, the scan showed additional lesions (four colonic and two ileal) in a further six patients with ileal or ileocolonic disease radiologically; colonoscopy confirmed the colonic lesions but was not attempted in the two with ileal disease.

In 10 subjects with ulcerative colitis results of the scan and barium enema correlated in four, and in six the scan suggested that disease extended more proximally than depicted by the barium enema. This was confirmed in three subjects who underwent colonoscopy. Thus out of a total of 39 subjects the isotope scan showed the same distribution of disease as barium studies in 24, a greater extent in 12 , and a lesser extent in three.

\section{RADIATION DOSAGE AND COST}

The estimated dose from $200 \mathrm{MBq}(5.4 \mathrm{mCi}){ }^{99 \mathrm{~m}} \mathrm{Tc}$ sucralfate is $0.005-$ $0.012 \mathrm{~Gy}(0.5-1 \cdot 2 \mathrm{rad})$ to the stomach, $0.0125-0.025 \mathrm{~Gy}(1 \cdot 25-2 \cdot 5 \mathrm{rad})$ to the intestine, and $0.001 \mathrm{~Gy}(0.1 \mathrm{rad})$ to the total body. ${ }^{16}$ For comparison, the

TABLE I-Results of ${ }^{99 m} T$ c sucralfate scanning

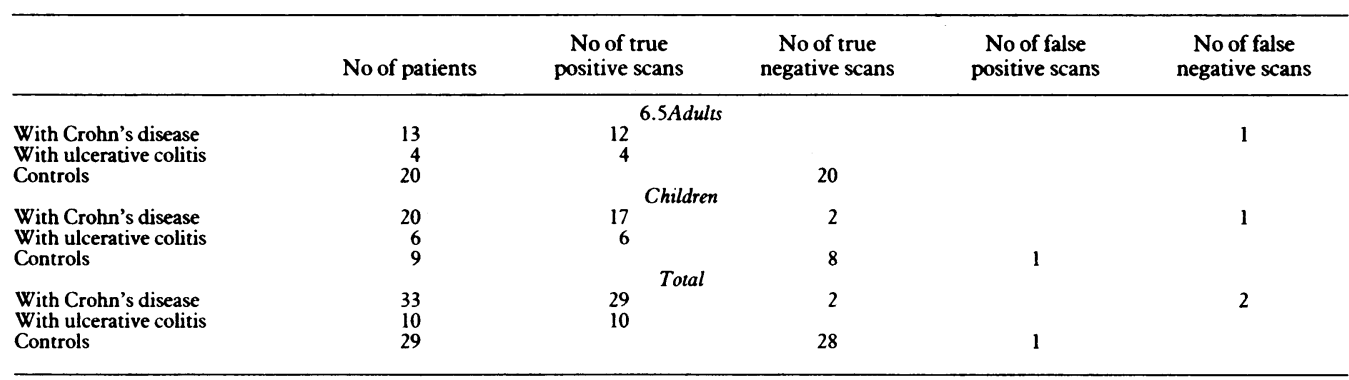

TABLE II-Sensitivity, specificity, and accuracy of the scan. Values are percentages

\begin{tabular}{lccccc}
\hline & & & \multicolumn{2}{c}{ Predictive value of: } \\
\cline { 5 - 7 } & Sensitivity & Specificity & Accuracy & Positive test & Negative test \\
\hline Adults $(n=37)$ & 94 & 100 & 97 & 100 & 95 \\
Children $(n=35)$ & 96 & 91 & 95 & 96 & 91 \\
\hline Total $(n=72)$ & 95 & 97 & 96 & 94 \\
\hline
\end{tabular}

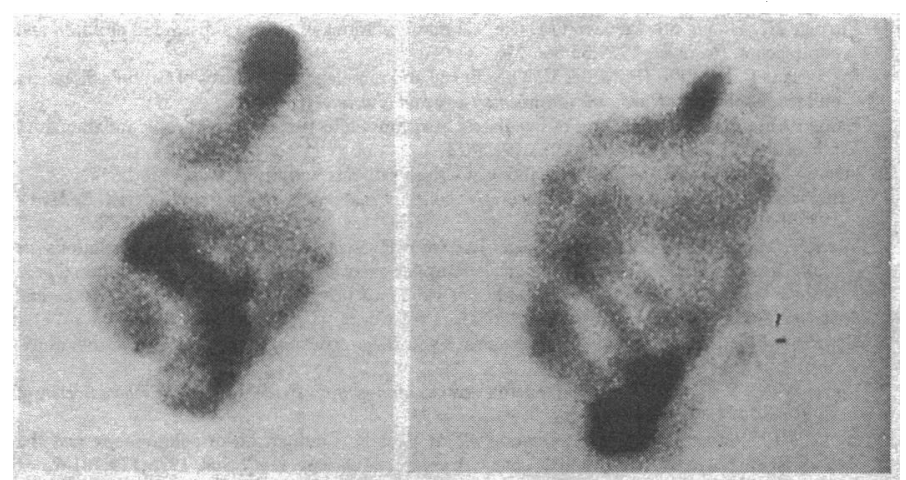

Ih

ant $2 h$

ant

Lh

ant $24 \mathrm{~h}$ calculated dosage for five minutes' abdominal fluoroscopy is $0.002-0.003 \mathrm{~Gy}$ $(0 \cdot 2-0 \cdot 3 \mathrm{rad})$ to the total body and $0 \cdot 05-0 \cdot 23 \mathrm{~Gy}(5-23 \mathrm{rad})$ to the skin, depending on age. ${ }^{17}$

The cost of ${ }^{99 m} \mathrm{~T} c$ sucralfate is about $£ 29$, directly comparable to the cost of $x$ ray film and contrast media. Personnel costs may be reduced as the permanent presence of a radiologist is unnecessary.

\section{Discussion}

The results of this study show that ${ }^{99 m} \mathrm{Tc}$ sucralfate detects active inflammatory bowel disease in adults and in children. False positive intestinal scans were not observed in patients with upper intestinal disease or the irritable bowel syndrome, the only false positive scan occurring in a patient with malrotation of the gut in whom delayed transit may have led to retention of isotope within the small bowel. The scan may be more sensitive than conventional radiology since, although negative scans were obtained in two patients with Crohn's colitis, additional lesions in either the colon or ileum were shown in six patients with Crohn's disease and more extensive disease was shown in six cases of ulcerative colitis; when performed colonoscopy confirmed the distribution depicted by the scan. The discrepancy between the results of the scan and radiology may be because radiology is insensitive in mild disease, ${ }^{18}{ }^{19}$ or it may be that the scan is capable of detecting microscopic colitis. ${ }^{2021}$ The scan offers further advantages over radiology and colonoscopy in that it is noninvasive, well tolerated, simple to perform, and provides information on both the small and large bowel. These features are especially important in children and the elderly in whom radiology may be of poor quality because of lack of patient cooperation. ${ }^{\prime}$ Furthermore, colonoscopy in children requires general anaesthesia or heavy sedation, is available only in specialised centres, ${ }^{1}$ and carries risk of perforation and bleeding,,$^{3.4}$ whereas the scan could be available in any hospital with scanning facilities.

It is not possible to equate directly the dose of radiation received from an orally ingested, non-absorbable compound in which the 
maximum dosage is to the intestine to that received during radiography in which the maximum dosage is to the skin overlying the area being studied. Nevertheless, the estimated dosage from this scan is less than that received during fluoroscopic screening and is much less than that associated with indium-111 scanning of granulocytes. ${ }^{17}$ This makes the scan attractive as a screening test and for repeated investigation in the serial assessment of disease activity.
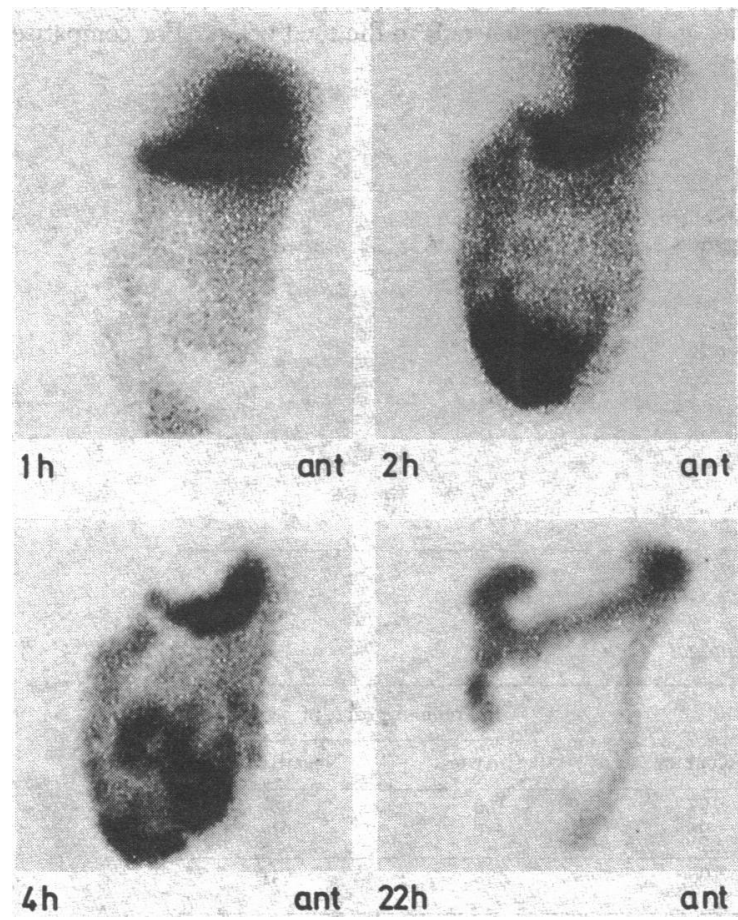

FIG $4{ }^{99 m} \mathrm{Tc}$ sucralfate scintigram in patient with ulcerative colitis. Early scans show no localised persistent uptake. At 22 hours there is uniform diffuse labelling of the whole colon with a pattern distinct from normal bowel (fig 1) and Crohn's colitis (fig 3).

The high sensitivity and specificity of the test also suggest that the scan may be useful in screening. As these results were obtained in a selected group of adults and children at a specialised referral centre the predictive value of the scan may be different in a district general hospital, where the incidence of inflammatory bowel disease might be lower. ${ }^{22}$ Furthermore, the test may not be specific for inflammatory bowel disease per se, but may detect mucosal abnormality in general as we have also observed positive scans in patients with salmonella infection and enterobius infestation (unpublished observations). This would not detract from its usefulness as a screening test.

The mechanism by which the compound outlines the mucosa in patients with Crohn's disease and ulcerative colitis is unknown. Sucralfate binds to bile salts, ${ }^{23}$ but this is unlikely to account for positive ileal scans as scans of controls were negative and reabsorption of bile salts is decreased in ileal Crohn's disease. Dissociation of technetium from sucralfate followed by its absorption and reexcretion may have occurred in some subjects as gastric images were occasionally observed on late scans (fig 2), but this seems unlikely to account for positive intestinal scans as in vitro studies show the label to be stable, positive intestinal scans were not seen in normal subjects, and no appreciable urinary excretion of radioisotope was noted during scanning. Furthermore, most subjects did not show gastric excretion (figs 3 and 4). Sucralfate probably binds to the small intestine and colon in a similar way to its binding to peptic ulcers. We have confirmed such binding to resected specimens of intestine affected with Crohn's disease (unpublished observation). Theoreti- cally, therefore, the technique should be able to differentiate active from inactive disease, a suggestion supported by the finding of negative scans in two patients with quiescent Crohn's disease in this study.

Granulocytes labelled with ${ }^{11}$ Id have been shown to be useful in determining the extent of inflammatory bowel disease ${ }^{15}{ }^{24}{ }^{25}$ and in assessing the severity of disease. ${ }^{26}{ }^{27}$ This technique, however, is expensive, its reliability has been questioned, and interpretation may be difficult because of increased background radioactivity secondary to uptake in the bone marrow, liver, and spleen. ${ }^{28}$ Clearly, ${ }^{99 m} \mathrm{Tc}$ sucralfate scanning cannot replace radiography or colonoscopy, nor can it detect extra luminal disease that may be depicted by the indium scan. Nevertheless, it offers a useful safe complement to these techniques and could be used in any district general hospital. It may prove a major advance in the investigation of inflammatory bowel disease.

We thank Ayerst Laboratories for a supply of pure sucralfate, the Department of Medical Physics, Christie Hospital and Holt Radium Institute, Manchester, for preparation of the labelled drug, and Mrs Y M Reed and Mrs E M Taylor for secretarial help.

\section{References}

1 Chong SKF, Bartram C, Campbell CA, Williams CB, Blackshaw AJ, Walker-Smith JA. Chronic inflammatory bowel disease in childhood. $\mathrm{Br} \mathrm{Med} f$ 1982;284:101-3.

2 Ekberg 0 . Crohn's disease of the small bowel examined by double contrast technique. A comparison with oral technique. Gastrointest Radiol 1977;i:355-8.

3 Smith LE. Complications of colonoscopy and polypectomy. Dis Colon Rectum 1976;19:407-12.

4 Livstone EM, Cohen GM, Troncale FJ, Touloukian RJ, Diastatic serosal lacerations: an unrecognised complication of colonoscopy. Gastroenterology 1974;67:1245-7.

5 Cotton PB, Williams CB. Practical gastrointestinal endoscopy. Oxford: Blackwell Scientific, 1982.

6 Nagashima R. Development and characteristics of sucralfate. I Clin Gastroenterol 1981;3 (suppl 2):103-10.

7 Nagashima R. Mechanisms of action of sucralfate. $\mathcal{C}$ Clin Gastroenterol 1981;3 (suppl 2):117-27.

8 Samloff IM. Inhibition of peptic aggression by sucralfate. The view from the ulcer crater. Scand $\mathcal{J}$ Gastroenterol 1983;18 (suppl 83):7-11.

9 Vasquez TE, Bridges RL, Braunstein P, Janshoit A-L, Meshkinpour H. Gastrointestinal ulcerations: detection using a technetium-99m-labelled ulcer-avid agent. Radiology 1983;148: 227-31.

10 Dawson DJ, Khan AN, Nuttall P, Shreeve DR. Technetium-99m-labelled sucralphate isotope scanning in the detection of peptic ulceration. Nuclear Medicine Communication 1985;6:319-25.

11 Burbige EJ, Huang SS, Bayless TM. Clinical manifestations of Crohn's disease in children and adolescents. Pediatrics 1975;55:866-71.

12 Macfarlane P, Ratcliffe JF, Miller V. The clinical and radiological diagnosis of Crohn's disease in children. Foumal of Paediatric Gastroenterology and Nutrition (in press).

13 Raine PAM. British Association of Paediatric Surgeons collective review: chronic inflammatory bowel disease. I Paediatr Surg 1984;19:18-23.

14 Harvey RF, Bradshaw JM. A simple index of Crohn's disease activity. Lancet 1980;i:514.

15 Truelove SC, Witts LJ. Cortisone in ulcerative colitis. Final report on a therapeutic trial. BrMed J 1955; ii: 1041-8.

16 Wu RK, Malmud LS, Knight LC, Siegel JA, Stern H, Zelac R. Radiation dose calculations for orally administered radiopharmaceuticals in upper gastrointestinal disease. In Raymon C, ed. Nuclear medicine and biology: proceedings of the Third World congress of nuclear medicine and biology. Paris: Pergamon Press 1982;2961-3.

17 Gordon I, Vivian G. Radiolabelled leucocytes: a new diagnostic tool in occult infection/inflammation. Arch Dis Child 1984;59:62-6.

18 Loose HWC, Williams CB. Barium enema versus colonoscopy. Proceedings of the Rayal Society of Medicine 1974;67:1033-6.

19 Wolff WI, Shinya H, Geffen A, Ozoktay S, de Beer R. Comparison of colonoscopy and the contrast enema in five hundred patients with colorectal disease. Am f Surg 1975;129:181-6.

20 Kingham JG, Levison DA, Ball JA, Dawson AM. Microscopic colitis-a cause of chronic watery diarrhoea. BrMed f 1982;285:1601-4.

21 Elliott PR, Williams CB, Lennard-Jones JE, et al. Colonoscopic diagnosis of minimal change colitis in patients with a normal sigmoidoscopy and normal air contrast barium enema. Lancel 1982;i:650-1.

22 Galen RS, Gambino SR. Beyond normality. New York: Wiley, 1975.

23 Caspary WF. The influence of glycocholic acid and sucralfate on transmural potential difference of the human stomach. In: Caspary WF, ed. Duodenal ulcer, gastric ulcer, sucralfate, a new therapeutic concept. Baltimore: Urban and Schwarzenberg, 1981;22-7.

24 Segal AW, Ensel J, Munro JM, Sarner M. Indium-111-tagged leucocytes in the diagnosis of inflammatory bowel disease. Lancet 1981;ii:230-2.

25 Saverymuttu SH, Peters AM, Hodgson HJ, Chadwick VS, Lavender JP. Indium-111 autologous leucocyte scanning: comparison with radiology for imaging the colon in inflammatory bowel disease. BrMed f 1982;285:255-7.

26 Saverymuttu SH, Peters AM, Lavender JP, Pepys MB, Hodgson HJ, Chadwick VS. Quantitative fecal Indium-111-labelled leukocyte excretion in the assessment of disease in Crohn's disease. Gastroenterology 1983;85:1333-9.

27 Saverymuttu SH, Lavender JP, Hodgson HJ, Chadwick VS. Assessment of disease activity in inflammatory bowel disease: a new approach using 111- In granulocyte scanning. $\mathrm{Br}$ Med $\mathcal{J}$ 1983;287:1751-3.

28 Buxton-Thomas MS, Dickinson RJ, Maltby P, Hunter JO, Wraight EP. Evaluation of indium scintigraphy in patients with active inflammatory bowel disease. Gut 1984;25:1372-75.

(Accepted 21 August 1985)

\section{w}

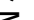
(1) . @ొ $\Rightarrow$ 